\title{
NÚCLEO DE APOIO À SAÚDE DA FAMÍLIA E TRABALHO INTERPROFISSIONAL: A EXPERIÊNCIA DO MUNICÍPIO DE CAMPINAS (SP)
}

\author{
FAMILY HEALTH SUPPORT CENTER AND INTERPROFESSIONAL LABOR: THE \\ EXPERIENCE OF THE MUNICIPALITY OF CAMPINAS (SÃO PAULO, BRAZIL)
}

NÚCLEO DE APOYO A LA SALUD DE LA FAMILIA Y TRABAJO INTERPROFESIONAL: LA EXPERIENCIA DEL MUNICIPIO DE CAMPINAS (SÃO PAULO, BRASIL)

\author{
Cristiane Pereira de Castro ${ }^{1}$ \\ Daniele Sacardo Nigro ${ }^{2}$ \\ Gastão Wagner de Sousa Campos ${ }^{3}$
}

Resumo Este estudo buscou compreender a dinâmica do processo de institucionalização do único Núcleo de Apoio à Saúde da Família implantado em Campinas, São Paulo. Embora seja município precursor da prática de apoio matricial, nele a implantação do Núcleo ocorre em ritmo lento, sendo relevante identificar fatores relacionados à inexpressiva presença deste arranjo organizacional, assim como analisar suas práticas. Optou-se pelo emprego do estudo de caso único, e para a produção de material empírico utilizou-se a observação participante e grupos focais. Os dados foram agrupados em dois eixos: a 'história feita', focalizando o contexto das políticas de saúde municipais; a 'história se fazendo', que remete à compreensão das percepções dos participantes daquela história. Observou-se que a experiência do Núcleo de Apoio à Saúde da Família estudado apresenta potencialidades e tensões. A metodologia do apoio matricial fundamenta a atuação da equipe e favorece o vínculo com a atenção básica, o desenvolvimento de uma relação interprofissional interativa, pautada no intercâmbio de conhecimentos e fortalecimento do trabalho em rede. Entretanto, as dificuldades para a ampliação desses núcleos como arranjo organizacional prioritário indicam a permanência de tensões que remetem ao histórico de conformação das práticas de matriciamento, pautadas em equipes autônomas e organizadas por áreas temáticas. Palavras-chave apoio matricial; Núcleo de Apoio à Saúde da Família; atenção primária à saúde.
Abstract This study had the aim of understanding the dynamics of the process of institutionalization of the only Family Health Support Center set up in the city of Campinas, in the state of São Paulo, Brazil. Even though the city is a pioneer in the practice of matrix support, in it, the establishment of the Center happens at a very slow pace, and it is relevant to identify the factors related to the inexpressive presence of this organizational arrangement, as well as to analyze its practices. We chose to make a single-case research, and, in order to produce the empirical material, we used participant observation and focal groups. The data were grouped in two axes: the 'made history', which focus on the context of the municipal health policies; and 'history in the making', which refers to the comprehension of the perceptions of the participants of that history. We observed that the experience of the studied Family Health Support Center presents potentialities and tensions. The matrix support methodology is the basis of the practice of the team, and favors the bond with primary health care, the development of an interactive interprofessional relationship, guided by the exchange of knowledge and the strengthening of the work in network. However, the difficulties in the expansion of these centers as an imperative organizational arrangement point to the permanence of the tensions regarding the history of the conformation of the matrix practices, which are based on independent teams and are organized by topics.

Keywords matrix support; Family Health Support Center; primary health care. 


\section{Introdução}

No cenário nacional, observa-se expansão do uso do apoio matricial, especialmente a partir do ano de 2008, com a publicação da portaria n. 154 (Brasil, 2008), quando o Ministério da Saúde oficializou a criação do Núcleo de Apoio à Saúde da Família (Nasf). Essa política prevê recursos financeiros destinados especificamente à contratação de profissionais para atuarem na função de apoio às equipes de saúde da família, as quais devem organizar seu processo de trabalho com base na metodologia do apoio matricial (Campos, Cunha e Figueiredo, 2013). Tal metodologia busca estimular a lógica da cogestão e do apoio nas relações interprofissionais, fortalecendo a constituição de equipes multiprofissionais que atuam com corresponsabilização e compromisso com a produção de saúde e do cuidado em rede (Campos et al., 2014).

Atualmente, o Nasf é regulamentado pela portaria 2.488, de 21 de outubro de 2011, e sua implantação tem ocorrido de maneira exponencial: em 2009, eram 952 equipes de Nasf e no primeiro trimestre de 2017 havia 3.797 equipes (Brasil, 2017). O vertiginoso processo de institucionalização da metodologia de apoio matricial por meio dos Nasfs evidencia a penetração de sua metodologia no Sistema Único de Saúde (SUS), o que justifica a realização de estudos que analisem sua efetividade.

A criação e o processo de implantação dos Nasfs expressam as potências produtivas de lógicas institucionais constitutivas dos movimentos instituintes, como analisado por Lourau (1975) e Lapassade, (1975), visto que a transformação de um arranjo organizativo em uma política sanitária revela o importante papel histórico da criação e institucionalização de marcos regulatórios, diretrizes e normas no âmbito do SUS. Tais normativas são capazes de "estabelecer hábitos ou padrões, [que] vigoram para regular as atividades sociais" (Baremblitt, 2002, p. 30), como é o caso das práticas interprofissionais no campo da saúde. Entretanto, na perspectiva da corrente teórica da análise institucional, o próprio processo de institucionalização conduz a um afastamento de sua energia pulsional geradora e a uma 'inexorável captura', que tende a se congelar, a se esclerosar e a adotar relações repetitivas e burocratizadas. Dessa reunião e imbricamento entre o instituído e o instituinte, resulta um circuito entre esses dois termos, em que as irrupções instituintes são transformadas em portarias, contratos e demais aparatos legais e institucionais, visando à implantação de novas práticas que sustentam uma política pública, como o Nasf pode ser considerado.

No âmbito das políticas públicas, não é novidade o reconhecimento de que há um conflito entre o que se enuncia e o que se faz. Há uma importante distância entre as políticas, os programas e os modelos de atenção e de gestão idealizados e as práticas concretas de produção de cuidado em saúde reali- 
zadas por profissionais e usuários, no cotidiano do SUS (Luz, 2004; Cecílio et al., 2012). A esse respeito, Baptista e Mattos (2011, p. 63, grifos do autor) afirmam que, no campo da análise de políticas, “é preciso romper com uma visão normativa e descritiva das políticas e trazer o que há de vida na sua construção", valorizando a produção cotidiana das políticas e ressaltando as diferenças, os conflitos e paradoxos que coexistem nesse processo.

O município de Campinas, em São Paulo, conta com uma rede de atenção básica composta por 63 centros de saúde, estimando-se que cada centro de saúde seja responsável por aproximadamente vinte mil habitantes. Os centros de saúde contam com equipes multiprofissionais, compostas por médicos das especialidades básicas (clínicos, pediatras, ginecologistas) ou médicos de família, enfermeiros, dentistas, auxiliares de enfermagem, auxiliares de consultório dentário e agentes comunitários de saúde (Campinas, 2017a). No período de desenvolvimento da pesquisa estavam implantadas estão implantadas 162 equipes de saúde da família, que cobrem $48 \%$ da população, e 142 equipes estão participando do $3^{\circ}$ Ciclo do Programa Nacional de Melhoria do Acesso e da Qualidade da Atenção Básica (Campinas, 2017b). O Nasf é objeto de interesse da gestão municipal e atualmente está em fase de implementação seis equipes-pilotos.

Embora o município de Campinas seja considerado o local onde a metodologia de apoio foi gerada e já tenha cumprido uma trajetória na prática de matriciamento, havia na cidade apenas uma equipe de Nasf (Castro, Oliveira e Campos, 2016). A implantação de Nasfs tem ocorrido em ritmo lento no município e, portanto, não seguiu a tendência expansionista identificada nas distintas regiões brasileiras.

São objeto de atenção neste artigo os fatores da inexpressiva presença do Nasf em Campinas, assim como suas práticas pautadas na metodologia do apoio matricial, que serão examinadas com base nos resultados de uma investigação de doutorado.

Diante da relevância dos novos arranjos organizativos que compõem a rede de atenção à saúde do SUS, este estudo buscou compreender a dinâmica do processo de institucionalização do único Nasf implantado em Campinas. Tal compreensão não se restringe apenas a esse município em particular, mas pretende alcançar outros locais nos quais essa experiência vem se instituindo, pois "é na prática política cotidiana das instituições e das relações sociais que podemos reconhecer elementos do nosso modo de constituir as políticas de Estado" (Baptista e Mattos, 2011, p. 65).

\section{Percurso metodológico}

A metodologia deste estudo está inserida no campo das pesquisas qualitativas (Minayo, 2000) e, devido às características do objeto em análise, optou-se 
pelo emprego do estudo de caso único (Yin, 2001). Investigamos o percurso histórico e a dinâmica do Nasf em Campinas, tomando-o como um analisador dos processos de institucionalização de uma política pública. O próprio dispositivo de pesquisa também constitui um analisador da instituição Nasf, porque o faz falar, mostrar suas contradições, seus limites e possibilidades (Lapassade, 1979; Lourau, 1975).

Segundo Yin (2001), nos estudos de caso trata-se de "expandir e generalizar teorias e não [de] enumerar frequências", isto é, de alcançar uma "generalização analítica", e não uma "generalização estatística". Em geral, os estudos de caso representam a estratégia preferida, quando se colocam questões do tipo 'como' e 'por quê'; quando o pesquisador tem pouco controle sobre os acontecimentos; quando o foco se encontra em questões contemporâneas inseridas em algum contexto da vida real, procurando-se compreender fenômenos sociais complexos. O estudo de caso do único Nasf em Campinas constitui "um caso decisivo", "um caso raro ou extremo" e "revelador", devido ao modo singular como se institui e organiza suas práticas (Yin, 2001, p. 30).

Os dados foram produzidos no contexto real do trabalho e das reuniões da equipe do Nasf, pois é uma premissa do método que o pesquisador se insira no mundo do objeto.

As técnicas utilizadas para a produção de dados foram a observação participante e grupos focais. Em cada uma dessas abordagens foram elaborados roteiros para orientar o trabalho em campo.

As observações foram realizadas com o objetivo de levantar informações sobre as práticas cotidianas dos profissionais que atuam no Nasf e seu papel de apoiador matricial junto às equipes de saúde da família. Para o registro das observações, foi utilizado o diário de campo, no qual foram anotados a descrição do local e dos sujeitos participantes, as atividades realizadas, informações prestadas por outras pessoas informalmente, enunciados verbais que constituem citações dos atores sociais em estudo e as impressões do pesquisador.

Quanto aos grupos focais, seu objetivo foi averiguar a percepção dos profissionais da saúde da família sobre o apoio matricial que recebem do Nasf. O roteiro do grupo focal foi construído exclusivamente para esta pesquisa, em torno de três eixos: percepções sobre as práticas de apoio matricial; efeitos do apoio matricial sobre o trabalho da equipe de saúde da família; e potencialidades e fragilidades do apoio matricial. Foram realizados quatro grupos focais (GFA, GFB, GFC, GFD), um para cada uma das equipes de saúde da família apoiadas pelo Nasf. Todos os grupos focais foram audiogravados, e a partir dos dados primários obtidos com a transcrição foram construídas narrativas, tal como sugerido por Ricoeur (1997).

Cada síntese elaborada com base nos grupos focais foi devolvida ao próprio grupo, para que este criticasse a narrativa elaborada pelos pesquisadores. 
Esses espaços de crítica foram denominados 'momentos reflexivos'. Destaquese que, nesses momentos, o material apresentado pelo pesquisador poderia ser complementado ou modificado e os profissionais puderam confirmar posições, rever argumentos, discutir diferenças entre aquilo que disseram e o modo como foram interpretados e compreendidos, podendo se reposicionar diante do próprio discurso e da tradição discursiva que o sustentava (Onocko Campos, 2005).

A análise do material empírico foi realizada com base na triangulação dos dados, conforme proposto por Minayo e colaboradores (2005). A partir da leitura realizada do diário de campo e das narrativas, foi constituída uma linha para a interpretação dos dados e emergiram dois eixos analíticos: a 'história feita', focalizando o contexto das políticas de saúde municipais, e a 'história se fazendo', remetendo à compreensão das percepções dos participantes daquela história. Partimos do reconhecimento de que os processos de institucionalização de práticas requerem a participação dos sujeitos e de que importa compreender os sentidos e atribuições diversas de cada participante para identificar a potência instituinte presente nos discursos e nas práticas. A ampla gama de questões que emergiu emergiu do segundo eixo 'história se fazendo' levou-nos a desdobrá-lo em três categorias empíricas: a metodologia de trabalho do Nasf e seus efeitos; o lugar de (in)visibilidade e (im)potência; e o lugar de protagonismo e intercâmbios.

Nesse percurso metodológico, partimos do pressuposto de que a implicação entre pesquisador e seu objeto de estudo constitui um fato, algo inexorável, independentemente da vontade consciente (Lourau, 2004; Coimbra e Nascimento, 2004). A implicação não pode ser tomada como sinônimo de engajamento ou envolvimento, uma vez que existe mesmo que não a desejemos (Monceau, 2008); trata-se de analisar mais o modo de implicação do que a sua quantidade, visto não poder ser medida. No âmbito da presente pesquisa, colocamo-nos também em análise ao escolher a dinâmica de constituição e o processo de trabalho do único Nasf de Campinas como objeto de estudo, visto que, como gestores, docentes e pesquisadores, participamos ativamente do processo de elaboração e desenvolvimento da metodologia de trabalho interprofissional utilizada nos Nasfs, o apoio matricial.

Inicialmente, a motivação para o desenvolvimento do estudo foi conhecer as formas pelas quais o Nasf realizava o matriciamento das equipes de saúde da família, considerando a possibilidade de transformar a própria pesquisa em um processo de educação permanente, com a universidade e os serviços de saúde produzindo conhecimento conjuntamente. Entretanto, escapou-nos na formulação das perguntas norteadoras do estudo uma questão central, qual seja: de que modo nós, da universidade, participamos e contribuímos para dificultar a expansão dos Nasfs em Campinas? Na condição de pesquisadores 
implicados, identificamos certa resistência da nossa parte a tirar conclusões acerca desse desafio, embora tenhamos percebido diversos deslocamentos e afetações provocados pelo encontro com os dados empíricos, que deverão ser tema de futura análise.

A pesquisa aqui relatada se desenvolveu no âmbito de investigação de doutorado aprovada pelo Comitê de Ética em Pesquisa da Faculdade de Ciências Médicas da Universidade Estadual de Campinas (Unicamp), mediante o parecer 438.490 .

\section{Resultados e Discussão}

\section{A história feita: o processo de implantação do Nasf em Campinas e seus desdobramentos}

Neste eixo, procuramos reunir fatos e eventos históricos de um determinado contexto - o município de Campinas, em um período definido -, ressaltando as descontinuidades e rupturas, os acasos e contingências que possibilitaram escolher caminhos, que culminou na inauguração e institucionalização do Nasf. Reconhecemos que não há uma evolução nos acontecimentos, mas um processo vivo em constante construção, que eventualmente sofre rupturas e que, em outros momentos, é apenas uma opção incremental de mudanças que poderiam ou não ocorrer (Baptista e Mattos, 2011). Daí a importância de destacarmos marcos ou eventos relevantes da história do processo de institucionalização do Nasf.

Em 2008, o município de Campinas iniciou as discussões sobre a implantação do Nasf, entretanto esse processo não havia avançado como nas demais regiões brasileiras, o que no discurso oficial se atribuía a razões de cunho administrativo e financeiro. O debate só foi retomado em meados de 2010, e em 2011 foi pactuado que seriam implantadas equipes piloto de Nasf no município e foram constituídas as três primeiras equipes, localizadas nos distritos de Saúde Sudoeste, Norte e Sul.

A curta trajetória das equipes organizadas nos distritos Norte e Sul deveuse, especialmente, às dificuldades dos profissionais que realizavam o apoio matricial em compor, de fato, um novo arranjo organizacional pautado na integração das áreas temáticas, criando uma nova identidade profissional.

Assim, no período de realização desta pesquisa, apenas a equipe do Distrito Sudoeste continuava funcionando no município e desenvolvendo suas atividades com quatro equipes de saúde da família, alocadas em um Centro de Saúde.

O ritmo lento envolvendo a implantação do Nasf em Campinas evidencia uma tensão presente na constituição histórica desse equipamento, pois 
ainda que houvesse o incentivo financeiro do governo federal, até o presente momento, este não produziu o efeito motivador de expandir essa política pública, como ocorreu nos demais municípios brasileiros. Também podem ter contribuído para a estagnação do Nasf questões de ordem ideológica presentes na cultura institucional do SUS Campinas, pautadas no receio de que a estruturação rígida do projeto Nasf nacional liquidasse com as experiências menos normatizadas de apoio matricial, espalhadas pela cidade desde o início dos anos 1990 (Braga Campos, 2000). Parte dos profissionais que atuavam no matriciamento por áreas - saúde mental, reabilitação, assistência farmacêutica, entre outras - demonstrou resistência à adesão ao modelo Nasf, que seria organizado sem novas contratações, ao mesmo tempo que a gestão municipal, por sua vez, demonstrava interesse em realizar os ajustes necessários para reorganizar as equipes nos Nasf com vistas a acessar o incentivo financeiro.

Tal tensão permanece, assim como o temor, entre os trabalhadores do SUS Campinas, de que a adesão à política de Nasf, como propugnada pelo governo federal, apague as iniciativas e práticas de matriciamento locais em toda a atenção básica, não apenas nas equipes de saúde da família.

Cabe destacar também que a presente pesquisa tem como foco a equipe de Nasf do Distrito Sudoeste, única equipe em funcionamento no período de coleta dos dados. Uma dessas equipes de saúde da família falou sobre o 'privilégio' de contar com o apoio do Nasf:

O município começou com três equipes de Nasf e foi diminuindo, sendo que agora só tem uma equipe, que é essa que está atuando no nosso Centro de Saúde. Aqui no Centro de Saúde nos sentimos privilegiados, mas não é justo os demais centros de Saúde não poderem contar com o trabalho do Nasf (GFB).

A equipe Nasf do Distrito Sudoeste foi criada aproximadamente em abril de 2011, com recursos humanos já existentes, não tendo havido novas contratações. As indicações para a constituição do Nasf levaram em consideração o perfil individual, a experiência do profissional e também o interesse de cada um em atuar no grupo. A primeira equipe foi constituída por uma fisioterapeuta, uma terapeuta ocupacional, uma nutricionista e uma psiquiatra.

Com o passar do tempo, a equipe Nasf ganhou novos profissionais, que vieram substituir demitidos, mas a lógica de composição da equipe nunca levou em consideração a recomendação proposta pelo Ministério da Saúde em suas publicações sobre o Nasf (Brasil, 2009, 2014), fato registrado em um dos grupos focais:

Segundo as legislações, a inserção do Nasf deve ser uma demanda combinada entre a equipe de saúde da família e gestão local, levando-se em consideração as 
questões que envolvem o território. Aqui não ocorreu dessa forma, o Nasf foi montado a partir da reorganização do apoio do distrito e da disponibilidade dos profissionais envolvidos, e não de uma demanda da unidade (GFA)

Como apenas uma equipe de Nasf era insuficiente para dar retaguarda para todas as equipes de saúde da família que atuavam no território, o Colegiado de Coordenadores de Unidades de Atenção Básica debateu o tema, e os seguintes critérios para a escolha das unidades básicas a serem apoiadas pelo Nasf foram pactuados: existência de reuniões da equipe de referência, comprometimento do coordenador local com a proposta Nasf e envolvimento da unidade no projeto de gestão da clínica. Para receber o suporte do Nasf, foram, então, escolhidas três unidades básicas que, juntas, abrigavam um total de dez ESFs.

No primeiro trimestre de 2012, com a saída, sem substituição, de duas profissionais da equipe Nasf, o número de equipes apoiadas se reduziu e o Nasf passou a atuar apenas em duas unidades básicas.

No final de 2012, houve incompatibilidade de projetos de trabalho entre o Nasf e as equipes de saúde da família que atuavam em uma das unidades básicas. Segundo os dados obtidos pela pesquisa, esse descompasso ocorreu por dois motivos. O primeiro é que a equipe de saúde da família compreendia que deveria ter acesso a vagas individuais dos profissionais do Nasf e agendar os casos conforme sua própria análise, sem discussão prévia (uma agenda ambulatorial com vagas semanais previamente definidas). Outro motivo foi a impossibilidade de estabelecer agendas compartilhadas entre os profissionais de nível superior do Nasf e as equipes de saúde da família, o que impossibilitava o desenvolvimento de atividades conjuntas. Apesar da interferência dos gestores na resolução desses impasses, não foi possível construir um consenso entre as equipes envolvidas e pactuou-se suspensão das atividades do Nasf no local. Assim, o Nasf manteve apoio a apenas uma unidade básica, composta por quatro equipes de saúde da família.

No período da observação participante, a equipe Nasf era composta por dois fisioterapeutas, psicóloga, assistente social, farmacêutica e médica psiquiatra. Vale ressaltar que alguns profissionais não têm dedicação exclusiva às atividades do Nasf e assumem outras atribuições, ligadas à atuação como referência da área técnica no Distrito Sudoeste (farmacêutica e assistente social) ou à assistência direta em um centro de saúde específico (psicóloga).

Analisando-se essa trajetória, constata-se que a gestão municipal optou por implantar o Nasf mediante o remanejamento dos profissionais que já atuavam no município, e não por articular sua construção com base nas necessidades do território e equipes de saúde da família, restringindo o debate aos coordenadores das unidades. Um dos grupos focais explicitou esse descompasso, 
o qual resultou em uma série de desencontros no que se refere ao início do trabalho da equipe Nasf:

Um dia o Nasf chegou do nada e simplesmente, na reunião de equipe do Centro de Saúde, os profissionais Nasf foram apresentados. Essa chegada foi bem complicada, pois os próprios profissionais do Nasf não tinham clareza do modo como deveriam funcionar, quais instrumentos de trabalho iriam utilizar. Isso trouxe insegurança, dúvidas, e nossa equipe explicitou esse descontentamento (GFA).

Entretanto, apesar dessas dificuldades iniciais, a atuação do Nasf foi, aos poucos, sendo construída e ressignificada, instituindo-se uma prática interprofissional compartilhada, como evidencia a narrativa a seguir:

Com o tempo compreendemos que essa questão foi superada, e atualmente existe entre nós uma relação interprofissional muito aberta (...), foi através da participação deles nas reuniões de equipe que juntos construímos nosso contrato de trabalho, juntos criamos sentido para o apoio matricial e estamos o tempo todo repactuando nosso trabalho, ou seja, modelamos o trabalho entre o Nasf e nós (GFB).

A trajetória do único Nasf no munícipio e sua sobrevivência, durante os últimos dez anos, a despeito do fato de a gestão municipal não tê-lo adotado como diretriz prioritária, é reveladora da interpenetração do instituinte no instituído. De um lado, equipes resistindo a mudanças e defendendo as práticas de apoio matricial por núcleos autônomos pautados em áreas temáticas. De outro, uma equipe de Nasf disposta a experimentar a nova proposta trazida pelo Ministério da Saúde, baseada na integração de profissionais das diversas categorias em um único arranjo organizacional. Os dados obtidos na observação evidenciaram que os profissionais do Nasf buscaram abrir brechas para a constituição de uma proposta diferente de matriciamento, respeitando a cultura institucional, ao mesmo tempo que romperam as fronteiras das áreas temáticas, tendo em vista a construção de novos conhecimentos e práticas interprofissionais interativas junto com as equipes de saúde da família.

\section{A história se fazendo...}

\section{Metodologia de trabalho do Nasf e seus efeitos}

A equipe Nasf realizava reuniões semanais, mas durante o período de observação a equipe completa esteve presente em poucos encontros, pois sempre havia conflito de agendas, já que nem todos os profissionais têm dedicação exclusiva às atividades Nasf. Além disso, havia encontros mensais 
para discussão de temas teóricos, definidos pelos profissionais. O tema discutido durante a observação foi 'educação em saúde', e nessa atividade estavam presentes todos os profissionais da equipe.

A equipe Nasf teve um coordenador durante os oito meses de seu funcionamento. Por escolha dos próprios profissionais, depois desse período optouse por trabalhar em colegiado, sem coordenador. Desta forma, observou-se um processo de autogestão, em que o coletivo se reconheceu como 'grupo disposto a aprender'.

Essa escolha da equipe Nasf propiciou avanços em direção à democracia no trabalho interprofissional, tendo resultado em horizontalização das relações interprofissionais por meio do compartilhamento de responsabilidades e decisões em cogestão sobre os processos de trabalho. Porém, nas observações foi possível identificar uma tendência ao isolamento e à desconexão em relação às necessidades das equipes de saúde da família, dos usuários e dos gestores.

No que se refere à supervisão e/ou apoio às atividades desenvolvidas, foi relatado que no início de suas atividades a equipe Nasf contou com outros profissionais ligados ao Distrito de Saúde acompanhando suas reuniões e pactos realizados com os coordenadores dos centros de Saúde e equipes de saúde da família. Esses supervisores também traziam elementos do contexto distrital (projetos, novas resoluções) e sugestões para modificar os processos de trabalho vivenciados pelo Nasf no apoio às equipes. Com o passar do tempo, esses profissionais externos foram se distanciando, devido a outras prioridades do distrito, e no período de observação a equipe não contava mais com esse suporte.

A falta de apoio ou supervisão para os profissionais do Nasf deu origem a um impasse, pois é por meio da criação de espaços permanentes de análise e reflexão que se constroem possibilidades de realimentação de sua potencialidade de transformar as práticas hegemônicas (Figueiredo e Onocko Campos, 2009). Além disso, a formação para o apoio depende da sistematização de reflexões sobre o cotidiano de trabalho com equipes e os usuários, reforçando a necessidade do espaço de supervisão externa para refletir sobre a prática, as angústias, as tensões e demais questões emergentes no cotidiano (Dimenstein et al., 2009).

Constatou-se que as atividades desenvolvidas pelo Nasf apresentavam dois públicos-alvo: as equipes de saúde da família e os usuários. As ações desenvolvidas eram: visitas domiciliares compartilhadas; discussões de caso; atendimento conjunto; atendimento individual; avaliação da demanda de fisioterapia da unidade; atividade de educação permanente com os agentes comunitários de saúde; reuniões de discussão de casos em saúde mental; participação nas reuniões das equipes de saúde da família; grupos educativos e de promoção da saúde; articulação com os demais serviços de saúde do ter- 
ritório, como Serviço de Atendimento Domiciliar, Centro de Reabilitação, e também articulação intersetorial com as escolas e com o Centro de Referência de Assistência Social (CRAS).

Portanto, a equipe Nasf utilizava diversas ferramentas para o desenvolvimento de suas atividades, contemplando a quase totalidade dos instrumentos recomendados pelo Ministério da Saúde (Brasil, 2009, 2014).

As reuniões da equipe de saúde da família eram o principal espaço de comunicação e de acionamento do suporte do Nasf, e a maioria dos pactos ocorria durante esse encontro, mediante discussão de casos. Entretanto, também ocorria acesso à equipe Nasf fora das reuniões para suporte aos casos imprevistos e urgentes. Essa facilidade de acesso à equipe Nasf foi registrada pelas equipes de saúde da família:

Existem espaços específicos, algumas agendas próprias para discutir questões que envolvem o apoio matricial e, na maior parte do tempo, respeitamos essa organização. Contudo, quando há um caso que não pode esperar, acionamos os profissionais Nasf fora da agenda sistemática, discutimos no corredor, por telefone, pelo WhatsApp, e juntos definimos qual será a conduta para o caso, com muita tranquilidade (GFB).

Um ponto importante na relação com o Nasf é o fato de a equipe estar sempre disponível para acolher as nossas demandas (mesmo fora das agendas pactuadas) e pensar numa forma de dar resposta, de se organizar para as coisas acontecerem de fato (GFC).

Observou-se também que os casos trazidos para discussão com o Nasf eram escolhidos espontaneamente por cada equipe de saúde da família e que não havia (formalmente instituída) nenhuma lista de critérios para orientar a seleção dos casos a serem compartilhados.

Percebeu-se que se dava prioridade a casos de vulnerabilidade social e subjetiva, atendendo, portanto, ao princípio da equidade, mas também refletindo a dificuldade dos profissionais de saúde da família para lidar com essa dimensão.

A falta de critérios para priorizar casos a serem compartilhados era vista de maneira positiva pela maioria das equipes de saúde da família, com exceção de uma equipe:

Enquanto equipe não sabemos quando podemos contar com o Nasf, em que reuniões o Nasf estará presente, em que situações específicas o Nasf poderá intervir junto com a equipe. $\mathrm{O}$ trabalho do Nasf acaba ocorrendo de forma não sistematizada, sendo tudo resolvido na hora da discussão de caso, e isso dificulta sabermos o momento de acionar o Nasf e em quais situações (GFA). 
Durante as observações, percebeu-se que nas equipes de saúde da família em que já havia a tradição de organizar os processos de trabalho com base na cogestão de saberes, poderes e afetos, as atividades desenvolvidas junto com a equipe Nasf aconteceram conforme acordos realizados, de maneira interativa, valorizando o 'fazer com', e não o 'fazer pelo outro'. Por sua vez, nas equipes em que o processo de trabalho apresentava características do modelo assistencial hegemônico, com poder centrado no profissional médico ou no enfermeiro, o profissional do Nasf enfrentava grandes dificuldades em realizar atividades com toda a equipe de saúde da família, e várias vezes as atividades combinadas não ocorriam. Nessas situações, evidenciou-se a importância de que a equipe do Nasf tenha flexibilidade e atue de forma propositiva, apresentando sugestões diferentes, ou seja, que valorize atividades com toda a equipe, mesmo que essa não fosse a demanda direta dos profissionais de saúde da família.

Outra questão importante se refere à realização de devolutivas da maioria dos casos acompanhados pela equipe Nasf às equipes de saúde família. As devolutivas geralmente ocorriam nas reuniões de equipe, verbalmente, e não havia um registro específico que facilitasse o monitoramento dos casos que estavam sendo acompanhados pelo profissional do Nasf e dos casos que eram devolvidos para as equipes de saúde da família.

Ficou evidente uma relação de troca entre os profissionais das várias equipes, havendo duplo ganho entre participantes do processo (aprender e ensinar), diferentemente de outras experiências de matriciamento que esses profissionais vivenciam em seu cotidiano:

A experiência de apoio que estamos vivenciando é diferente das outras experiências de apoio matricial que conhecemos. Geralmente, o profissional que realiza o apoio matricial é acionado para ajudar com um tema (...), algumas atividades pontuais compartilhadas, depois simplesmente vai embora. Nesse modelo, o apoiador vem, diz como deve ser conduzido o caso, e pronto. Ele não sabe e também não leva em consideração as dificuldades da equipe. Quando surgem dúvidas, temos dificuldade de acionar novamente o apoiador, ou seja, para nós é um apoio matricial duro (GFB).

A possibilidade de organização interprofissional das práticas e a constatação da 'dureza' do apoio matricial indicam que a valorização do saber técnico, pontual, inflexível nas agendas tende a produzir algo muito próximo aos processos instituídos que, por sua natureza, vão perdendo, pouco a pouco, o vigor e a potência de criação e invenção próprios da dimensão instituinte. Entretanto, cabe destacar a relevância de lançar mão de protocolos e outras ferramentas normativas que contribuam para organizar os processos de trabalho, tendo em vista a integralidade do cuidado. Mais do que instrumentos de controle 
por parte da gestão, especialmente da produtividade dos trabalhadores, tais recursos podem favorecer o monitoramento e o alcance da integralidade do cuidado, daí sua relevância.

\section{Lugar de (in)visibilidade e (im)potência}

Um ponto que gerou polêmica entre os profissionais da equipe Nasf foi a demanda, por parte da coordenação da unidade e do distrito, pela instituição de um registro de todas as ações desenvolvidas pelo Nasf, em um sistema informatizado, a fim de que a produção pudesse ser visualizada. Essa demanda não foi atendida porque a equipe Nasf, até o final da observação, não havia sido cadastrada no Ministério da Saúde. Essa situação pode ser compreendida como um impasse decorrente da predominância, nos serviços de saúde, da lógica hierárquica, burocrática e centrada em procedimentos coexistindo com as diretrizes democráticas do apoio matricial (Bonfim et al., 2013).

$\mathrm{O}$ trabalho desenvolvido pelo Nasf traz, devido à multiplicidade de estratégias adotadas, uma dimensão singular definida por cada caso e intervenção coletiva realizada, o que dificulta sua incorporação em uma planilha com códigos predefinidos. O desafio parece residir na elaboração de novos formatos que consigam refletir, explicitar e contabilizar as diversas ações produzidas pelos profissionais que atuam no Nasf.

Os gestores de Campinas têm sido pouco flexíveis quanto ao debate dessa questão e também quanto ao pedido constante dos profissionais de que a equipe Nasf seja formalizada e credenciada no Mistério da Saúde. Isso tem gerado um sentimento de insegurança e frustração na equipe do Nasf estudado, que tem tido dificuldades para mostrar a natureza do seu trabalho, sem desconectá-lo da realidade vivenciada com as equipes de saúde da família. Argumentaram sobre a importância de quantificar as ações sem, entretanto, desqualificá-las, colocando na agenda municipal a discussão do projeto político institucional previsto para o Nasf.

Uma equipe de saúde da família também destacou, nos grupos focais, o distanciamento dos gestores no que se refere à articulação dos processos de trabalho entre equipes de saúde da família e equipe Nasf:

O descompasso entre o que o Nasf tem a oferecer e o que a equipe do Centro de Saúde precisa ou espera é algo que ainda não foi superado. Acreditamos que isso pode ser resolvido com a presença de uma gestão ativa, que ajude tanto o Nasf quanto a equipe de saúde da família a construir na prática esse novo arranjo organizacional (GFA).

Diversos estudos atestam que o apoio do gestor local facilita a implantação de novos arranjos organizacionais como o Nasf; contudo, até o momento isso 
ainda não se configurou como uma realidade no município, e o frágil apoio por parte da gestão à incorporação do Nasf tem levado a um impasse. A implantação de programas como o Nasf, que visam a reorganizar o trabalho em saúde, depende de vontade política, entretanto está ficando cada vez mais nítido o descompasso entre os tempos da gestão e o ritmo de transformação das práticas cotidianas (Bezerra e Dimenstein, 2008; Jorge et al., 2012; Onocko Campos et al., 2012).

Contudo, identificou-se nesta observação que o frágil apoio da gestão, embora gere ruídos e desconforto, não paralisa a continuidade das ações desempenhadas pelo Nasf. O que se percebeu foi o desenvolvimento de estratégias para escapar de amarras burocráticas administrativas, mantendo-se distanciamento das demandas que interferem negativamente no desenvolvimento de ações, pois a manutenção da autonomia dos profissionais na construção de seus processos de trabalho significa a possibilidade de se articularem para responder às demandas apresentadas pelas equipes de saúde da família.

Chama atenção a dificuldade de conciliar o horário dos profissionais Nasf com o dos profissionais da equipe de saúde da família, o que em algumas situações cria obstáculos ao desenvolvimento do trabalho conjunto. Percebeu-se interesse e desejo de ambas as equipes de realizar atividades compartilhadas, mas também dificuldades:

Temos dificuldade de realizar atendimentos conjuntos, pois as agendas dos profissionais da equipe e do Nasf dificilmente coincidem. Ainda assim, apesar da dificuldade, conseguimos juntos buscar uma solução que não traga reflexos para os usuários ou aumento no tempo de espera pelos atendimentos (GFB).

O SUS Campinas conta com uma quantidade insuficiente de serviços de retaguarda especializada, e em algumas situações a equipe Nasf tem assumido o papel de outros níveis de atenção. Não foi pouco frequente observar atendimentos individuais de casos que, devido à sua complexidade, deveriam estar em um centro de referência especializado. Cunha e Campos (2011) afirmam que a falta de serviços de saúde especializados pode conduzir a um funcionamento equivocado do Nasf, que assume o papel de substituto dos serviços que faltam na rede assistencial, na tentativa de responder à demanda da população.

Essas situações são razão constante de preocupação, frequentemente apontada pelas equipes de saúde da família:

Uma questão importante é a ausência quase total de alguns profissionais na rede do município, como nutricionista, psiquiatra, entre outros. Observamos também uma quantidade insuficiente de serviços de referência especializados para dar conta da demanda dos casos que exigem uma atuação específica. Compreendemos que o 
Nasf não deve ser utilizado como tapa-buraco, e o correto é que o SUS Campinas fortaleça sua rede assistencial para que ela seja de fato completa e resolutiva (GFC).

Em vários momentos, também ficou clara a importância de se aumentar a frequência de algumas ações compartilhadas ou individuais, mas isso raramente tem sido possível, devido aos limites de infraestrutura. Diversos estudos registram que os impasses para a implantação efetiva do apoio matricial estão ligados diretamente à superação de problemas estruturais e organizacionais que ainda fazem parte do cotidiano do SUS (Arona, 2009; Lancman e Barros, 2011; Santos e Lacaz, 2012; Azevedo et al., 2013; Dimenstein et al., 2009; Pena et al., 2012; Pinto et al., 2012).

Além disso, perceberam-se também conflitos em relação ao cardápio de ofertas do Nasf, que nem sempre é divulgado para toda a equipe da unidade básica, como demonstrado no grupo focal:

Nasf não tem um cardápio de ofertas claro, que nos ajude a compreender a função dos profissionais e automaticamente facilitar os fluxos de apoio matricial entre eles e a nossa equipe. Em algumas situações, não sabemos como eles podem nos ajudar, no que podemos pedir ajuda, o que é possível de ser compartilhado (GFA).

A observação permitiu identificar que isso ocorre por dois motivos: o fato de o Nasf priorizar a organização da agenda individual do seu profissional e a inexistência de um espaço formal coletivo definido para tornar de conhecimento público essas atividades; sem esse espaço, a divulgação ocorria de maneira informal, restringindo a informação.

\section{Lugar de protagonismo e intercâmbios}

O estudo revelou que atuação da equipe Nasf junto com as equipes de saúde da família, apesar das tensões enfrentadas, tem ampliado a resolutividade das ações e possibilitado intercâmbio de conhecimento em questões assistenciais que envolvem o processo de trabalho dessas equipes.

Segundo Silva et al. (2012), para o êxito do trabalho do Nasf é essencial que ocorram trocas de conhecimentos dialógicas que fortaleçam as práticas de saúde e em especial na atenção básica, na qual ninguém é detentor de todo o saber necessário.

Durante a observação, foi possível identificar que a troca de saberes entre profissionais Nasf e equipe de saúde da família ocorria de duas maneiras. A primeira, por meio de capacitação sobre temas específicos, tais como manejo de tentativas de suicídio e uso abusivo de drogas, programa bolsa família e sua interface com a atenção básica, violência doméstica, atualização sobre medica- 
mentos disponibilizados na unidade. A segunda, durante o desenvolvimento das atividades compartilhadas, em especial a visita domiciliar, projetos terapêuticos singulares, grupos educativos e reorganização das filas. As equipes de saúde da família fizeram os seguintes apontamentos sobre essa questão:

O Nasf traz muito suporte para a questão educativa, tanto para os usuários, através dos grupos, e para a equipe, através da discussão de alguns temas específicos (GFA).

Uma coisa importante realizada pelos fisioterapeutas do Nasf foi a organização da fila da unidade por critérios de risco. Eles avaliaram todos os usuários que estavam na fila e organizaram um fluxo para casos que deveriam ir para a referência municipal, casos que seriam acompanhados por eles na unidade, casos que ficariam sob a responsabilidade da equipe (GFC).

A participação do Nasf nos grupos é muito interessante, em especial no antigo grupo de hipertensos e diabéticos, que estava parado. Com a inserção do Nasf, ele ganhou vida novamente, pois eles ajudam na elaboração das propostas para o grupo, na organização das atividades e agora, com a farmacêutica, estamos também entregando a medicação no grupo (GFD).

Ao observar as atividades compartilhadas, verificou-se que, mesmo havendo diferenças entre o Nasf e a equipe de saúde da família, estes funcionavam como uma equipe ampliada. Isso só foi possível porque se fortaleceu o vínculo entre os profissionais, se instituiu a corresponsabilização compartilhada e se adotou um objetivo comum. Em alguns momentos das atividades compartilhadas o saber especializado se sobressaiu, mas isso não gerou conflito entre os diferentes profissionais e possibilitou um trabalho interprofissional articulado que valorizava a atuação de cada profissional envolvido em uma rede de cuidados.

Na observação das atividades compartilhadas, foi possível identificar um processo de educação permanente dos profissionais envolvidos, seja pela ampliação do olhar sobre a situação de saúde vivenciada pelos usuários, seja pelo aumento da capacidade de intervir de maneira direta na resolutividade dos casos.

Uma função desempenhada pelo Nasf era a articulação intersetorial com os serviços no território, como escolas e Cras, visando à melhoria das condições de saúde da população. Essa atuação do Nasf foi importante para a construção da rede de cuidados, conforme relato de uma equipe de saúde da família:

Na nossa visão, o Nasf apoia nas nossas necessidades, sejam necessidades internas dentro da unidade ou externas, acionando outros serviços da rede. Desenvolvem 
uma rede multidisciplinar, sempre buscando nos ajudar na resolução dos casos e complementar o nosso trabalho. O trabalho do Nasf sempre faz diferença, sempre aprendemos, sempre agrega uma visão nova (GFD).

Outro ponto importante da prática de apoio matricial desenvolvida pela equipe Nasf é a discussão do processo de trabalho das equipes de saúde da família, identificada tanto na observação quanto nos grupos focais:

O Nasf realiza um pouco do papel que esperamos do apoiador institucional, ou seja, o Nasf problematiza com a equipe questões para discutir com a gestão local, faz intermediação dessas questões e consegue ampliar a visão, pois não são profissionais da equipe do Centro de Saúde. Atualmente o apoiador institucional, em Campinas, faz apoio ao gestor e não para a equipe, é um apoio distante e sem sentido para a maioria de nós (GFA).

Essa percepção trazida pelos profissionais está em consonância com o observado no estudo realizado por Fernandes e Figueiredo (2015) sobre a organização do processo de trabalho dos apoiadores institucionais em Campinas, cujos resultados indicaram que o gestor local (coordenador do serviço de saúde) é o principal sujeito das ações de apoio institucional e que o trabalhador e usuário só são incluídos em algumas situações:

Um ponto importante é os profissionais do Nasf nos ajudarem a pensar questões que envolvem o processo de trabalho, como organização da agenda da equipe. Eles até já fazem isso, mas consideramos importante que isso acontecesse mais vezes; eles nos ajudarem não apenas nas questões assistenciais, mas também atuarem na organização do processo de trabalho (GFB).

Em geral, observou-se esforço da equipe do Nasf na instituição de uma prática articulada, baseada em uma relação interprofissional solidária, conforme as necessidades registradas pelas equipes de saúde da família, sejam assistenciais ou ligadas ao processo de trabalho.

\section{Considerações finais}

Neste estudo verificou-se que a trajetória de implantação e os processos de trabalho experimentados pela única equipe Nasf do município de Campinas apresenta potencialidades e tensões.

A adoção da metodologia de apoio matricial como eixo primordial da organização do processo de trabalho do Nasf contribuiu para a instituição de um vínculo de parceria e para o desenvolvimento de uma relação interprofissional interativa, pautada no intercâmbio de conhecimentos e no fortalecimento do 
trabalho em rede. Em vários momentos, observou-se uma prática articulada entre a equipe Nasf e equipes de saúde da família, seja nas questões assistenciais ou naquelas relativas ao processo de trabalho.

Entretanto, a experiência do Nasf gerou diversas tensões, ancoradas principalmente nas diferenças entre o modelo municipal adotado para as práticas de matriciamento pautadas em equipes autônomas e organizadas por áreas temáticas e o modelo do Nasf, trazido pelo Ministério da Saúde, que propõe a integração das áreas temáticas em uma única equipe de matriciamento. Além disso, no cotidiano de trabalho da equipe Nasf com as equipes de saúde da família perceberam-se momentos de distanciamento entre as necessidades das equipes de saúde da família e a atuação próxima dos especialistas, ao privilegiar os núcleos de saberes específicos, às vezes perdendo de vista a importância de se evitar a hierarquização, o especialismo e a fragmentação do cuidado.

Cabe, portanto, continuar investigando em que medida o Nasf, com a utilização da metodologia do apoio matricial, se configura como uma práxis dinâmica, capaz de lidar com a necessidade de estruturação prévia e de improvisação diante de diferentes situações, não se congelando em uma ação estável reconhecida como meio e fim definidos a priori. Trata-se de um arranjo organizacional que a cada dia, a cada novo processo vivenciado, a cada nova prática instituída mantém viva a possibilidade de recriação.

\section{Colaboradores}

Todos os autores trabalharam na concepção do estudo, redação e aprovaram a versão para publicação. 
Resumen Este estudio busca comprender la dinámica del proceso de institucionalización del único Núcleo de Apoyo a la Salud de la Familia implantado en la ciudad de Campinas, estado de São Paulo. Si bien se trata de un municipio precursor en la práctica de apoyo matricial, la implantación del Núcleo se produce a un ritmo lento, siendo importante identificar los factores relacionados a la inexpresiva presencia de esta estructura organizacional, así como analizar sus prácticas. Se optó por el uso del estudio de caso único, y para la elaboración de material empírico se utilizó la observación participante y grupos focales. Los datos se agruparon en dos ejes: la 'historia hecha', centrado en el contexto de las políticas de salud municipales; y la 'historia en desarrollo', que hace referencia a la comprensión de las percepciones de los participantes de aquella historia. Se observó que la experiencia del Núcleo de Apoyo a la Salud de la Familia estudiado presenta potenciales y tensiones. La metodología del apoyo matricial da fundamentos al trabajo en equipo y favorece el vínculo con la atención básica, el desarrollo de una relación interprofesional interactiva basada en el intercambio de conocimientos y el fortalecimiento del trabajo en red. Sin embargo, las dificultades para la ampliación de estos núcleos como estructura organizacional prioritaria indican la persistencia de tensiones relacionadas a la conformación histórica de las prácticas con apoyo matricial, basadas en equipos autónomos y organizados por áreas temáticas.

Palabras clave apoyo matricial; Núcleo de Apoyo a la Salud de la Familia; atención primaria de la salud.

\section{Notas}

${ }^{1}$ Universidade de São Paulo, Faculdade de Saúde Pública, Departamento de Política, Gestão e Saúde.

<crispcastro@gmail.com>

Correspondência: Rua Francisco de Assis Pupo, 83, apartamento 302, Bloco 1, Vila Industrial, CEP 13035-000, Campinas, São Paulo, Brasil.

${ }^{2}$ Universidade Estadual de Campinas, Faculdade de Ciências Médicas, Departamento de Saúde Coletiva, Campinas, São Paulo, Brasil.

$<$ danielesacardo@gmail.com>

${ }^{3}$ Universidade Estadual de Campinas, Faculdade de Ciências Médicas, Departamento de Saúde Coletiva, Campinas, São Paulo, Brasil.

<gastaowagner@mpc.com.br> 


\section{Referências}

ARONA, Elizabete C. Implantação do matriciamento nos serviços de saúde de Capivari. Saúde e Sociedade, São Paulo, v. 18, supl. 1, p. 26-36, 2009.

AZEVEDO, Dulcian M. et al. Apoio matricial em saúde mental: percepção de profissionais no território. Revista de Pesquisa: cuidado é fundamental online, Rio de Janeiro, v. 5, n. 1, p. 3.311-3.322, 2013.

BAPTISTA, Tatiana W. F.; MATTOS, Ruben A. Sobre política (ou o que achamos pertinente refletir para analisar políticas). In: MATTOS, Ruben A.; BAPTISTA, Tatiana W. F. (orgs.). Caminhos para análise das politicas de saúde [versão on line]. Rio de Janeiro: IMS/Uerj, Ensp/Fiocruz, EPSJV/Fiocruz, 2011. p. 52-91. Disponível em: <www.ims.uerj.br/ccaps>. Acesso em: 9 set. 2015.

BAREMBLITT, Gregório F. Compêndio de análise institucional e outras correntes. Belo Horizonte: Instituto Félix Guattari, 2002.

BEZERRA, Edilane; DIMENSTEIN, Magda. Os CAPS e o trabalho em rede: tecendo o Apoio Matricial na Atenção Básica. Psicologia: Ciência e Profissão, Brasília, v. 28, n. 3, p. 632-645, 2008.

BONFIM, Iris G. et al. Apoio matricial em saúde mental na atenção primária à saúde: uma análise da produção científica e documental. Interface: Comunicação, Saúde, Educação, Botucatu, v. 17, n. 45, p. 287-300, 2013.

BRAGA CAMPOS, Florianita C. O modelo da reforma psiquiátrica brasileira e as modelagens de São Paulo, Campinas e Santos. Tese (Doutorado em Saúde Coletiva) - Faculdade de Ciências Médicas, Universidade Estadual de Campinas, Campinas, 2000.
BRASIL. Ministério da Saúde. Portaria n. 154, de 24 de janeiro de 2008. Dispõe sobre a criação dos Núcleos de Apoio à Saúde da Família. Diário Oficial da União, Poder Executivo, Brasília, DF, 25 jan. 2008, Seção 1, fls. 38 a 42 .

BRASIL. Ministério da Saúde. Diretrizes do Nasf: Núcleo de Apoio à Saúde da Família. Brasília: Secretaria de Atenção à Saúde, Departamento de Atenção Básica, 2009. (Cadernos de Atenção Básica, 27).

BRASIL. Ministério da Saúde. Núcleo de Apoio a Saúde da Família: ferramentas para a gestão e para o trabalho cotidiano. Brasília: Secretaria de Atenção à Saúde, Departamento de Atenção Básica, 2014. (Cadernos de Atenção Básica, 39).

BRASIL. Departamento de Atenção Básica. Sala de Apoio à Gestão Estratégica. Disponível em: <http://sage.saude.gov.br/>. Acesso em: 30 jun. 2017.

CAMPINAS. Prefeitura Municipal. Secretaria Municipal de Saúde. Rede Municipal de Saúde. Disponível em: <http://www.saude. campinas.sp.gov.br/saude/>. Acesso em: 3 jun. 2017a.

CAMPINAS. Prefeitura Municipal. Secretaria Municipal de Saúde. Relatórios de Gestão. Relatório anual de gestão 2016. Disponível em: <http://www.saude.campinas.sp.gov. br/saude/>. Acesso em: 30 de jun. 2017b.

CAMPOS, Gastão W. S.; CUNHA, Gustavo T.; FIGUEIREDO, Mariana D. Práxis e formação Paideia: apoio e cogestão em saúde. São Paulo: Hucitec, 2013.

CAMPOS, Gastão W. S. et al. A aplicação da metodologia Paideia e sua aplicação no apoio institucional, no apoio matricial e na clínica ampliada. Interface: Comunicação, Saúde, 
Educação, Botucatu, n. 18, supl. I, p. 983995, 2014.

CASTRO, Cristiane P.; OLIVEIRA, Mônica M.; CAMPOS, Gastão W. S. Apoio matricial no SUS Campinas: análise da consolidação de uma prática interprofissional na rede de saúde. Ciência \& Saúde Coletiva, Rio de Janeiro, v. 21, n. 5, p. 1.625-1.636, 2016.

CECÍLIO, Luiz C. O. et.al. A atenção básica à saúde e a construção das redes temáticas de saúde: qual pode ser o seu papel? Ciência \& Saúde Coletiva, Rio de Janeiro, v. 17, n. 11, p. 2.893-2.902, 2012.

COIMBRA, Cecília M. B.; NASCIMENTO, Maria L. Sobreimplicação: prática de esvaziamento político? Niterói: Universidade Federal Fluminense, 2004. Disponível em <www.slab. uff.br>. Acesso em: 6 jul. 2017.

CUNHA, Gustavo T.; CAMPOS, Gastão W. S. Apoio matricial e atenção primária em saúde. Saúde e Sociedade, São Paulo, v. 20, n. 4, p. 961-970, 2011.

DIMENSTEIN, Magda et al. O apoio matricial em unidade de saúde da família: experimentando inovações em saúde mental. Saúde e Sociedade, São Paulo, v. 18, n. 1, p. 63-74, 2009.

FERNANDES, Juliana A.; FIGUEIREDO, Mariana D. Apoio institucional e cogestão: uma reflexão sobre o trabalho dos apoiadores do SUS Campinas. Physis: Revista de Saúde Coletiva, Rio de Janeiro, v. 25, n. 1, p. 287-306, 2015.

FIGUEIREDO, Mariana D.; ONOCKO CAMPOS, Rosana. Saúde mental na atenção básica à saúde de Campinas, SP: uma rede ou um emaranhado? Ciência \& Saúde Coletiva, Rio de Janeiro, v. 14, n. 1, p. 129-138, 2009.

JORGE, Maria S. B. et al. Ferramenta matricial na produção do cuidado integral na estratégia saúde da família. Acta Paulista de Enfermagem, São Paulo, v. 25, n. 2, p. 26-32, 2012.

LANCMAN, Selma; BARROS, Juliana O. Estratégia de Saúde da Família (ESF), Núcleo de
Apoio à Saúde da Família (Nasf) e terapia ocupacional: problematizando as interfaces. Revista de Terapia Ocupacional da Universidade de São Paulo, São Paulo, v. 22, n. 3, p. 263-269, 2011.

LAPASSADE, Georges. A entrada na vida. Lisboa: Edições 70, 1975.

LAPASSADE, Georges. El analizador y el analista. Barcelona: Gedisa, 1979.

LOURAU, René. A análise institucional. Petrópolis: Vozes, 1975.

LOURAU, René. Implicação e sobreimplicação. In: ALTOÉ, Sonia (org.). René Lourau: analista institucional em tempo integral. São Paulo: Hucitec, 2004. p. 186-198.

LUZ, Madel T. Fragilidade social e busca de cuidado na sociedade civil de hoje. In: PINHEIRO, Roseni et al. (orgs.). Cuidado: as fronteiras da integralidade. Rio de Janeiro: Hucitec, 2004. p. 9-20.

MINAYO, Maria C. S. O desafio do conhecimento: pesquisa qualitativa em saúde. São Paulo: Hucitec; Rio de Janeiro: Abrasco, 2000.

MINAYO, Maria C. S. et al. Métodos, técnicas e relações em triangulação. In: MINAYO, Maria Cecília S. et al. (orgs.). Avaliação por triangulação de métodos: abordagem de programas sociais. Rio de Janeiro: Editora Fiocruz, 2005. p. 71-103.

MONCEAU, Gilles. Implicação, sobreimplicação e implicação profissional. Fractal: revista de psicologia, Niterói, v. 20, n. 1, p. 19-26, 2008.

ONOCKO CAMPOS, Rosana. Pesquisa qualitativa em políticas, planejamento e gestão em saúde coletiva. In: BARROS, Nelson F. et al. (orgs.). Pesquisa qualitativa em saúde: múltiplos olhares. Campinas: Editora Unicamp, 2005. p. 261-271.

ONOCKO CAMPOS, Rosana; CAMPOS, Gastão W.S.; FERRER, Ana L. Avaliação de estratégias inovadoras na organização da atenção primária 
à saúde. Revista de Saúde Pública, São Paulo, v. 46, n. 1, p. 43-50, 2012.

PENA, Paulo F. A. et al. Cuidado ao paciente com doença renal crônica no nível primário: pensando a integralidade e o matriciamento. Ciência \& Saúde Coletiva, Rio de Janeiro, v. 17, n. 11, p. 3.135-3.144, 2012.

PINTO, Antonio G. A. et al. Apoio matricial como dispositivo do cuidado em saúde mental na atenção primária: olhares múltiplos e dispositivos para resolubilidade. Ciência \& Saúde Coletiva, Rio de Janeiro, v. 17, n. 3, p. 653-660, 2012.

RICOEUR, Paul. Tempo e narrativa. Campinas: Papirus, 1997.
SANTOS, Ana P. L; LACAZ, Francisco A. C. Apoio matricial em saúde do trabalhador: tecendo redes na Atenção Básica do SUS, o caso de Amparo, SP. Ciência \& Saúde Coletiva, Rio de Janeiro, v. 17, n. 5, p. 1.150-2.012, 2012.

SILVA, Andréa T. C. et al. Núcleos de Apoio à Saúde da Família: desafios e potencialidades na visão dos profissionais da Atenção Primária do município de São Paulo, Brasil. Cadernos de Saúde Pública, Rio de Janeiro, v. 28, n. 11, p. 2.076-2.084, 2012.

YIN, Robert K. Estudo de caso: planejamento e métodos. Porto Alegre: Bookman, 2001.

Recebido em 06/03/2017. Aprovado em 15/09/2017. 